\title{
Hygienic conditions of the processing environment and microbial loads of Tra fish (Pangasius hypophthalmus): Trimming step
}

\author{
Tu C. Nguyen ${ }^{1}$, Hang T. M. Nhan ${ }^{1}$, Tam N. T. Huynh ${ }^{2}$, \& Ngoc T. A. Tong ${ }^{1 *}$ \\ ${ }^{1}$ Department of Food Technology, Faculty of Agriculture, Can Tho University, Vietnam \\ ${ }^{2}$ Biotechnology Research and Development Institute, Can Tho University, Vietnam
}

ARTICLE INFO
Research Paper
Received: November 01, 2020
Revised: March 19, 2021
Accepted: March 29, 2021
Keywords
Hygiene
Microorganisms
Pangasius
Quality
Trimming
*Corresponding author
Tong Thi Anh Ngoc
Email: ttangoc@ctu.edu.vn

\section{ABSTRACT}

During the processing of frozen Pangasius hypophthalmus fillets, the microbiological counts depend on the source of raw materials and processing conditions, those impact significantly on the quality of the final product. In particular, trimming is considered a high-risk step of cross-contamination during processing. This study aimed to compare and evaluate the microbial quality at trimming step in four frozen Pangasius processing factories located in the Mekong Delta region. Trimmed Pangasius fillet and contact surfaces samples (i.e., gloves and processing tools) were examined including total mesophilic counts, Coliforms, E. coli and coagulase-positive Staphylococci (Staphylococci coa+). The results showed that total mesophilic counts on trimming Pangasius processed in $\mathrm{A}, \mathrm{B}, \mathrm{C}$ and D plant were $7.1 \pm 0.4 ; 7.5 \pm 0.7 ; 6.7 \pm 1.1$ and $6.0 \pm 0.4$ $\log \mathrm{CFU} / \mathrm{g}$, respectively. Coliforms, E. coli and Staphylococci coat on trimmed Pangasius ranged $4.0-5.1 ; 2.1-3.7$ and $1.8-4.2 \log \mathrm{CFU} / \mathrm{g}$, respectively. Thus, proper preservation of fillets during processing is suggested. Good manufacturing practices should implement effectively to minimize the risk of cross-contamination for the trimmed fillets.

Cited as: Nguyen, T. C., Nhan, H. T. M., Huynh, T. N. T., \& Tong, N. T. A. (2021). Hygienic conditions of the processing environment and microbial loads of Tra fish (Pangasius hypophthalmus): Trimming step. The Journal of Agriculture and Development 20(2), 44-50. 


\title{
Điều kiện vệ sinh của môi trường chế biến và mật số vi sinh vật trên cá Tra (Pangasius hypophthalmus): Công đoạn chỉnh hình
}

\author{
Nguyễn Cẩm Tú ${ }^{1}$, Nhan Thị Mỹ Hằng ${ }^{1}$, Huỳnh Ngọc Thanh Tâm² \& Tống Thị Ánh Ngọc ${ }^{1 *}$ \\ ${ }^{1}$ Bộ Môn Công Nghệ Thực Phẩm, Khoa Nông nghiệp, Trường Đại Học Cần Thơ, Cần Thơ \\ ${ }^{2}$ Viện Nghiên Cứu và Phát Triển Công Nghệ Sinh Học, Trường Đại Học Cần Thơ, Cần Thơ
}

\section{THÔNG TIN BÀI BÁO \\ Bài báo khoa học \\ Ngày nhận: 01/11/2020 \\ Ngày chỉnh sửa: 19/03/2021 \\ Ngày chấp nhận: 29/03/2021}

\section{Từ khóa}

Cá Tra

Chất lượng

Chỉnh hình

Vệ sinh

Vi sinh vật

\section{*Tác giả liên hệ}

Tống Thị Ánh Ngọc

Email: ttangoc@ctu.edu.vn

\section{TÓM TẮT}

Trong quá trình chế biến cá Tra phi lê đông lạnh, mật số vi sinh vật phụ thuộc vào nguồn nguyên liệu và điều kiện chế biến và do đó có ảnh hưởng đáng kể đến chất lượng của thành phẩm. Chỉnh hình được xem là công đoạn có nguy cơ cao lây nhiễm trong quy trình chế biến. Nghiên cứu này được thực hiện nhằm đánh giá và so sánh mật số vi sinh vật tại công đoạn chỉnh hình ở bốn nhà máy chế biến cá Tra phi lê đông lạnh thuộc khu vực Đồng bằng sông Cửu Long. Mẫu cá chỉnh hình và môi trường chế biến (các bề mặt tiếp xúc như găng tay công nhân và dụng cụ chế biến) được đánh giá các chỉ tiêu vi sinh vật bao gồm: vi sinh vật tổng số hiếu khí, Coliforms, E. coli và Staphylococci dương tính coagulase (Staphylococci coa+). Kết quả cho thấy mật số vi sinh vật tổng số hiếu khí trên cá chỉnh hình ở bốn nhà máy $\mathrm{A}, \mathrm{B}, \mathrm{C}$ và $\mathrm{D}$ lần lượt là $7,1 \pm 0,4 ; 7,5 \pm 0,7 ; 6,7 \pm$ 1,1 và $6,0 \pm 0,4 \log C F U / g$. Mật số Coliforms, E. coli và Staphylococci coa+ trên cá chỉnh hình tại các nhà máy tương ứng dao động từ 4,0 - 5,1; $2,1-3,7$ và $1,8-4,2 \log \mathrm{CFU} / \mathrm{g}$. Nghiên cứu thấy rằng cần có phương pháp bảo quản phù hợp cá bán thành phẩm trong suốt quá trình chế biến. Thực hành vệ sinh và sản xuất tốt cần được thực hiện hiệu quả để giảm thiểu nguy cơ nhiễm chéo cho cá bán thành phẩm.

\section{1. Đặt Vấn Đề}

Cá Tra là loài có giá trị thương phẩm cao và được nuôi nhiều ở các tỉnh thuộc khu vực Đồng bằng sông Cửu Long như Đồng Tháp, An Giang, Cần Thơ, Vĩnh Long với tổng diện tích lên đến 6,6 nghìn ha (VASEP, 2019). Ngành hàng cá Tra là một trong những sản phẩm xuất khẩu chủ lực của ngành thủy sản và thị trường cá Tra được tiếp tục xuất khẩu sang 134 quốc gia và vùng lãnh thổ (VASEP, 2021). Tuy nhiên, nguy cơ sản phẩm không đảm bảo an toàn vệ sinh do việc thực hiện các hệ thống quản lý chất lượng không theo qui chuẩn, chưa hiệu quả và còn nhiều bất cập trong triển khai và áp dụng thực tế tại nhiều doanh nghiệp (Tong \& ctv., 2014).

Trong qui trình chế biến, chỉnh hình là một trong những công đoạn chế biến quan trọng ở giữa quy trình nhằm làm sạch, loại bỏ phần thịt đỏ, da, mỡ, và xương còn sót; ngoài ra đây là công đoạn tạo hình giúp các miếng cá phi lê đồng nhất về hình dạng và cảm quan. Ngoài ra, đây là công đoạn có nguy cơ cao gây mất an toàn vệ sinh thực phẩm do các bề mặt tiếp xúc (găng tay công nhân, dụng cư chế biến...) có thể là nguồn lây nhiễm vi sinh vật cho cá nếu không được kiểm soát tốt, thời gian chế biến dài và được tiến hành thủ công; nhiệt độ cũng có thể là nguyên nhân dẫn đến sự mất an toàn của sản phẩm (Tong \& ctv., 2014). Do đó, công đoạn chỉnh hình còn được xem là điểm kiểm soát (CP-control point) trong kế hoạch HACCP (phân tích mối nguy và kiểm soát tại các điểm tới hạn) cần được giám sát và kiểm soát trong quá trình chế biến.

Vì các lí do trên, nghiên cứu này thực hiện nhằm so sánh và đánh giá chất lượng vệ sinh tại công đoạn chỉnh hình ở bốn nhà máy chế biến cá Tra thuộc khu vực đồng bằng sông Cửu Long. Nội dung nghiên cứu được thực hiện thông qua đánh giá mật số vi sinh vật của cá Tra và môi 
trường chế biến tại công đoạn chỉnh hình; từ đó nghiên cứu cung cấp thêm thông tin, cũng như khuyến cáo và đề xuất phù hợp để góp phần giảm thiểu nguy cơ nhiễm chéo cho bán thành phẩm.

\section{Vật Liệu và Phương Pháp Nghiên Cứu}

\subsection{Vật liệu nghiên cứu}

Mẫu cá Tra, bề mặt tiếp xúc - bao gồm mẫu găng tay công nhân và mẫu dụng cụ chế biến (dao, thớt, rổ, mặt bàn chế biến) được lấy tại công đoạn chỉnh hình ở bốn nhà máy chế biến: A (100 tấn nguyên liệu/ngày, tọa lạc tại Vĩnh Long; các tiêu chuẩn an toàn thực phẩm áp dụng: HACCP và HALAL; thị trường xuất khẩu: Trung Quốc, Malaysia và Indonesia), B (100 tấn nguyên liệu/ngày, toạ lạc tại Đồng Tháp; các tiêu chuẩn an toàn thực phẩm áp dụng: ISO, HACCP, BRC, IFS và GLOBAL GAP; thị trường xuất khẩu: Châu Âu, Mỹ, Úc và các nước Châu Á), C (250 tấn nguyên liệu/ngày, toạ lạc tại An Giang; các tiêu chuẩn an toàn thực phẩm áp dụng: BRC, IFS, HACCP, HALAL và ASC; thị trường xuất khẩu: Nam Mỹ, Mexico, Châu Âu, Trung Đông, Trung Quốc-Hồng Kông và các nước Châu Á) và $\mathrm{D}$ (35 tấn nguyên liệu/ngày, toạ lạc tại Cần Thơ; các tiêu chuẩn an toàn thực phẩm áp dụng: HACCP, BRC và IFS; thị trường xuất khẩu: Anh, Hy Lạp, Ai Cập, Trung Đông, Thái Lan).

\subsection{Phương pháp lấy mẫu}

Mẫu cá chỉnh hình (1 - 2 miếng phi lê) được lấy bằng nhíp đã khử trùng và cho vào túi vô trùng (Stomacher bags, BagLight ${ }^{\circledR}$, Pháp); mẫu bề mặt tiếp xúc được lấy bằng cách sử dụng tăm bông đã được làm ẩm bằng dung dịch Maximum Recovery Diluent (MRD, Merck, Darmstadt, Đức); quét đều tăm bông theo chiều ngang, dọc và chéo trên bề mặt cần lấy mẫu với diện tích là $50 \mathrm{~cm}^{2}$; sau đó đặt lại tăm bông vào ống chứa dung dịch MRD để sử dụng cho phân tích các chỉ tiêu vi sinh vật (ISO 18593:2004).

Các mẫu sau khi lấy được ghi nhãn, cho vào túi vô trùng và bảo quản trong thùng đá, sau đó vận chuyển về phòng thí nghiệm vi sinh của nhà máy lấy mẫu hoặc của Bộ môn Công nghệ thực phẩm, Trường Đại học Cần Thơ; số lượng mẫu và chỉ tiêu phân tích được trình bày trong Bảng 1.

\subsection{Phương pháp phân tích vi sinh vật}

$25 \mathrm{~g}$ mẫu cá chỉnh hình được lấy từ các phần khác nhau của miếng phi lê, cho vào túi dập mẫu vô trùng; sau đó thêm vào $225 \mathrm{~mL}$ dung dịch MRD để thu được nồng độ pha loãng $10^{-1}$. Tiến hành dập mẫu (5 - 7 phút), sau đó tiến hành pha loãng mẫu bằng cách hút $1 \mathrm{~mL}$ mẫu cần pha loãng cho vào ống nghiệm chứa $9 \mathrm{~mL}$ dung dịch MRD để thu được nồng độ pha loãng $10^{-2}$. Đồng nhất mẫu trong 10 giây bằng máy vortex (RSVA10, PHOENIX, Đức) và lặp lại thao tác đến khi thu được các bộ ba nồng độ đổ đĩa thích hợp (pha loãng mẫu đạt đến nồng độ $10^{-6}$ ) (ISO 68872:2003). Đối với mẫu bề mặt tiếp xúc thì cần đồng nhất mẫu trong 10 giây bằng máy vortex trước khi tiến hành pha loãng.

Vi sinh vật tổng số hiếu khí (TMC - Total Mesophylic Counts) được xác định theo phương pháp đổ đĩa bằng môi trường Plate Count Agar (PCA, Merck, Darmstadt, Đức) và ủ ở $37^{\circ} \mathrm{C}$ trong 48 72 giờ; Coliforms và $E$. coli được xác định bằng môi trường Coliform Agar Enhanced Selectivity (Coliform Agar ES, Merck, Darmstadt, Đức) và ủ ở $37^{\circ} \mathrm{C}$ trong 24 giờ. Các khuẩn lạc Coliforms mọc trên môi trường có màu từ hồng đến đỏ, các khuẩn lạc E. coli (thuộc nhóm Coliforms) có màu từ xanh dương đến tím (Hình 1-A). Staphylococci dương tính coagulase (Staphylococci coa + ) được xác định bằng phương pháp trang đĩa trên thạch Baird Parker Agar (BPA, Merck, Darmstadt, Đức) bổ sung 25/500 mL Egg Yolk Tellurite Emulsion (EYTE, Merck, Đức). Sau 48 - 72 giờ ủ ở $37^{\circ} \mathrm{C}$, các khuẩn lạc Staphylococci coa+ có màu xám đen và tạo thành vùng kết tủa màu trắng đục xung quanh (Hình 1-B). Các khuẩn lạc Staphylococci được xác nhận dương tính coagulase bằng phản ứng tạo đông sử dụng thuốc thử Bactident ${ }^{\circledR}$ Coagulase (Merck, Darmstadt, Germany) (TCVN 4830-1:2005). Mỗi nồng độ đổ (trang) đĩa được lặp lại hai lần cho tất cả các chỉ tiêu phân tích.
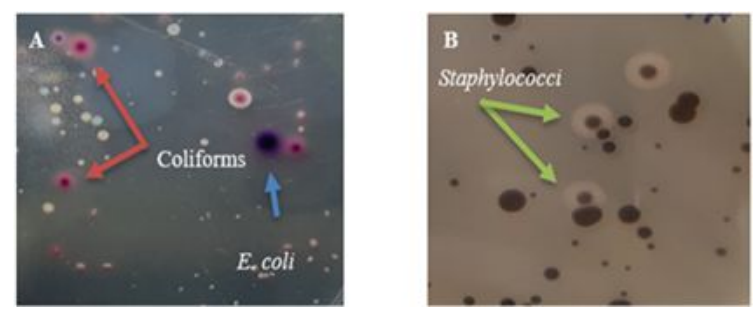

Hình 1. Hình thái khuẩn lạc Coliforms, E. coli (A) và Staphylococci coa+ (B). 
Bảng 1. Số lượng mẫu và chỉ tiêu vi sinh vật

\begin{tabular}{|c|c|c|c|c|}
\hline Loại mẫu $\quad$ Chỉ tiêu & Vi sinh vật tổng số & Coliforms & E. coli & Staphylococci coa $+^{1}$ \\
\hline Cá & $36^{2}$ & 36 & 36 & 36 \\
\hline Găng tay công nhân & 36 & 36 & 36 & 36 \\
\hline Dụng cụ chế biến & 36 & 36 & 36 & -3 \\
\hline
\end{tabular}

${ }^{1}$ Staphylococci dương tính coagulase; ${ }^{2} \mathrm{Ba}$ thời điểm lấy mẫu $\times$ ba ngày $\times$ bốn nhà máy; ${ }^{3}$ Không phân tích.

\subsection{Xử lý số liệu}

Mật số vi sinh vật được tính toán và biểu diễn dưới dạng đơn vị logarit của số khuẩn lạc hình thành: $\log \mathrm{CFU} / \mathrm{g}$ (cá) và $\log \mathrm{CFU} / 100 \mathrm{~cm}^{2}$ (bề mặt tiếp xúc). Kết quả được trình bày dưới dạng trung bình \pm độ lệch chuẩn và xử lý thống kê bằng kiểm định ANOVA $(\alpha=0,05)$ thông qua phần mềm Statgraphics Centurion 18 (Statgraphics Technologies, Inc., The Plains, Virginia).

\section{Kết Quả và Thảo Luận}

\subsection{Vi sinh vật tổng số, Coliforms, E. coli và Staphylococci coa+ trên găng tay công nhân}

Kết quả mật số vi sinh vật tổng số hiếu khí, Coliforms, E. coli, Staphylococci coa+ trên găng tay công nhân chỉnh hình ở bốn nhà máy chế biến được thể hiện ở Hình 2. Kết quả cho thấy, mật số vi sinh vật tổng số hiếu khí trên găng tay công nhân chỉnh hình dao động từ 5,7 - 7,7 log $\mathrm{CFU} / 100 \mathrm{~cm}^{2}$. Trong đó, mật số vi sinh vật tổng số hiếu khí trên găng tay công nhân chỉnh hình ở ba nhà máy $\mathrm{A}, \mathrm{B}$ và $\mathrm{C}$ cao hơn ý nghĩa so với nhà máy $\mathrm{D}(P<0,05)$. Mật số Coliforms trên găng tay công nhân ở nhà máy $\mathrm{A}$ cao nhất $(6,5$ $\left.\pm 0,6 \log \mathrm{CFU} / 100 \mathrm{~cm}^{2}\right)$ và khác biệt ý nghĩa $(P<0,05)$ so với ở các nhà máy còn lại (dao động từ 4,7 - 5,1 $\log \mathrm{CFU} / 100 \mathrm{~cm}^{2}$ ). Trong khi đó, mật số $E$. coli trên găng tay công nhân chỉnh hình dao động từ $2,6-3,4 \log \mathrm{CFU} / 100 \mathrm{~cm}^{2}$ và không khác biệt ý nghĩa giữa các nhà máy $(P$ $>0,05)$. Staphylococci coa+ trên găng tay công nhân chỉnh hình tại nhà máy $\mathrm{A}, \mathrm{B}$ và $\mathrm{C}(3,5-4,7$ $\left.\log \mathrm{CFU} / 100 \mathrm{~cm}^{2}\right)$ và khác biệt ý nghĩa so với nhà máy $\mathrm{D}\left(1,2 \pm 0,2 \log \mathrm{CFU} / 100 \mathrm{~cm}^{2}\right)$. Không có sự tương quan có ý nghĩa được tìm thấy giữa năng suất nguyên liệu và mật số vi sinh vật trên găng tay công nhân chỉnh hình giữa các nhà máy. Việc định lượng các vi khuẩn Coliforms, E. coli hoặc Staphylococci có thể được dùng như các chỉ thị để đánh giá hiệu quả của các quá trình vệ sinh và chương trình HACCP tại các nhà máy chế biến thực phẩm nói chung (Lang \& ctv., 1999), do đó lượng vi sinh vật tồn tại trong suốt qui trình chế biến phản ánh hiệu quả của hệ thống quản lí chất lượng, phụ thuộc vào các yếu tố như quy trình vệ sinh, phương pháp phòng ngừa đối với sản phẩm, cũng như kiểm soát sự lây nhiễm nước và nguyên liệu đầu vào.

Nghiên cứu của Noseda \& ctv. (2013) tại một nhà máy chế biến cá Tra (năng suất nguyên liệu 200 tấn/ngày) đã báo cáo rằng mật số $E$. coli trên găng tay công nhân chỉnh hình nhỏ hơn 0,7 $\log \mathrm{CFU} / 100 \mathrm{~cm}^{2}$ ở tất cả các mẫu. Tuy nhiên, mật số $E$. coli trên găng tay công nhân chỉnh hình trong nghiên cứu này cao hơn. Bên cạnh đó, Staphylococci coa+ trên găng tay công nhân chỉnh hình tại các nhà máy $\mathrm{A}, \mathrm{B}$ và $\mathrm{C}$ dao động từ 3,5 - 4,7 log CFU/100 $\mathrm{cm}^{2}$ (Hình 2). Staphylococcus aureus thuộc họ Staphylococci được biết là loài vi khuẩn gây ngộ độc thực phẩm và có thể phát triển nhanh ở khoảng nhiệt độ dao động trên cá chỉnh hình $\left(22-28^{\circ} \mathrm{C}\right.$ tại các nhà máy chế biến thực hiện trong nghiên cứu này). Ngoài ra, chúng còn được biết đến với khả năng hình thành màng sinh học (Di Ciccio \& ctv., 2015) trên các bề mặt chế biến thực phẩm do quá trình làm sạch và khử trùng không hiệu quả, và được sử dụng như một chỉ thị về mức độ vệ sinh cá nhân và thực hành sản xuất tốt (Da Silva Meira \& ctv., 2012; Tong \& ctv., 2020). Việc thực hiện các nghiên cứu tiếp theo chuyên sâu hơn về sự tồn tại và phát triển của loài vi khuẩn này trong qui trình chế biến là cần thiết. Vì vậy, các nhà máy cần chú trọng trang bị đầy đủ bảo hộ lao động (găng tay, khẩu trang, lưới trùm tóc,...) cho công nhân đồng thời giám sát việc tuân thủ thực hiện các qui phạm vệ sinh.

Vi sinh vật nói chung tồn tại với lượng cao trên găng tay công nhân (Hình 2) có thể là nguồn lây nhiễm vi sinh vật cho cá bán thành phẩm (đặc biệt là vi sinh vật gây bệnh) và do đó ảnh hưởng đến an toàn của cá thành phẩm (Svanevik \& ctv., 2015; Novoslavskij \& ctv., 2016). Vì vậy, các nhà 


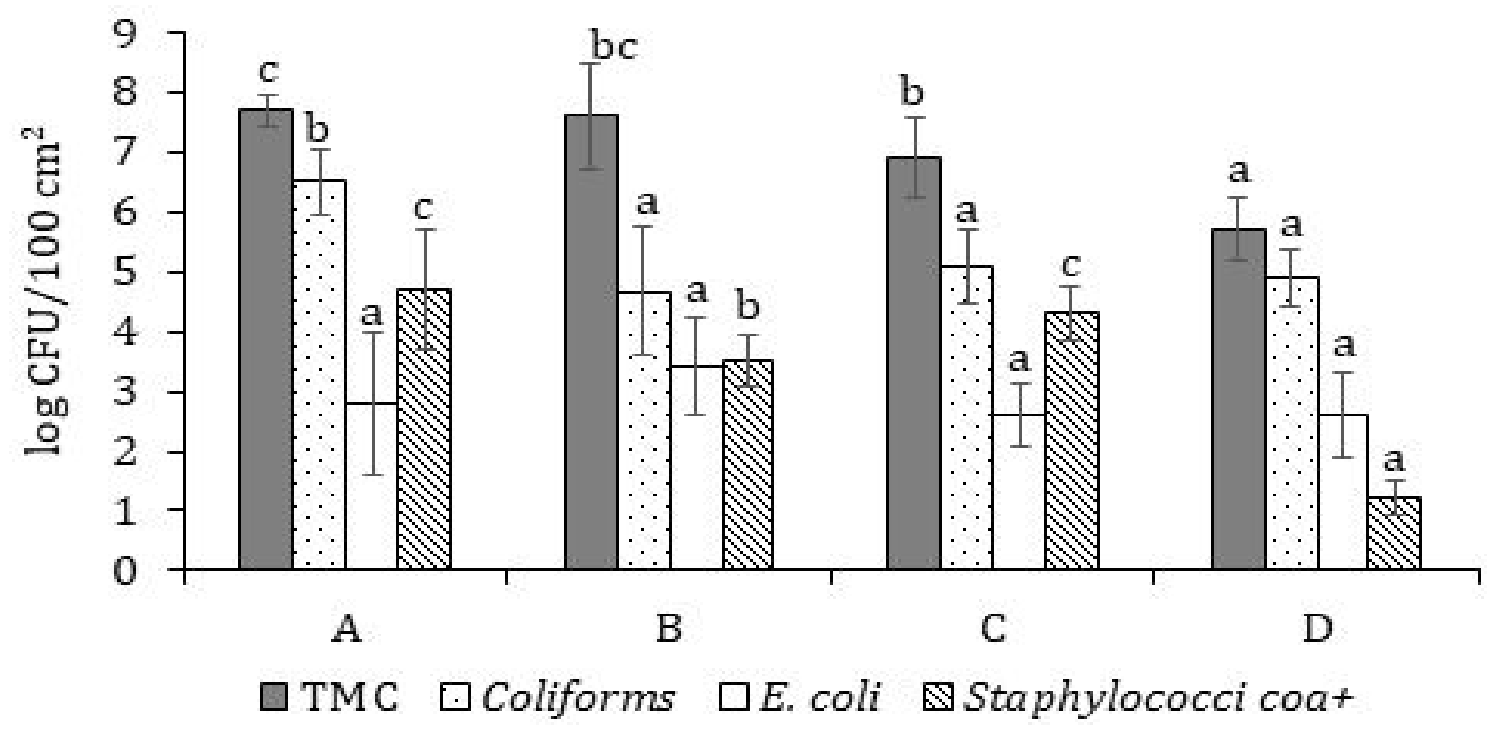

Hình 2. Vi sinh vật tổng số, Coliforms, E. coli và Staphylococci coa+ trên găng tay công nhân. Các chữ cái $(a, b, c)$ của cùng một chỉ tiêu vi sinh vật khác nhau thì các giá trị trung bình có sự khác biệt ý nghĩa thống kê ở mức $5 \%$.

máy cần tăng cường tần suất vệ sinh găng tay công nhân, dụng cư chế biến, nhà xưởng cũng như kiểm soát tốt nhiệt độ và thời gian cá tồn lưu tại công đoạn chỉnh hình. Ngoài ra, các quá trình làm sạch, khử trùng và thủ tục vệ sinh cá nhân, găng tay, bảo hộ lao động cần được kiểm soát chặt chẽ hoặc cải tiến bởi chúng có ảnh hưởng đến hệ vi sinh vật tồn tại trên găng tay công nhân.

\subsection{Vi sinh vật tổng số, Coliforms và $E$. coli trên dụng cụ chỉnh hình}

Những dụng cụ dùng trong quá trình chế biến là các bề mặt tiếp xúc trực tiếp với cá chẳng hạn như dao, thớt, rổ chứa, mặt bàn chế biến cũng có thể tiềm ẩn nguy cơ gây nhiễm chéo vi sinh vật cho cá nếu điều kiện vệ sinh và khử trùng không đảm bảo (Shikongo-Nambabi \& ctv., 2011; Novoslavskij \& ctv., 2016). Hình 3 thể hiện kết quả mật số vi sinh vật tổng số hiếu khí, Coliforms và $E$. coli trên dụng cụ chỉnh hình ở các nhà máy chế biến cá Tra. Cụ thể, mật số vi sinh vật tổng số hiếu khí trên dụng cụ chỉnh hình tương đối cao, dao động từ $6,5-7,9 \log \mathrm{CFU} / 100 \mathrm{~cm}^{2}$. Mật số Coliforms trên dụng cụ chỉnh hình tại nhà máy A $\left(6,4 \pm 1,1 \log \mathrm{CFU} / 100 \mathrm{~cm}^{2}\right)$ cao hơn ý nghĩa so với ở các nhà máy còn lại $(P<0,05$; dao động từ $\left.4,3-5,2 \log \mathrm{CFU} / 100 \mathrm{~cm}^{2}\right)$. Ngược lại, mật số $E$. coli trên dụng cư chỉnh hình tại nhà máy A là $1,9 \pm 0,7 \log \mathrm{CFU} / 100 \mathrm{~cm}^{2}$ và thấp hơn so với các nhà máy còn lại (dao động từ 2,5 - 3,1 log CFU $/ 100 \mathrm{~cm}^{2}$ ) (Hình 3). Không có sự tương quan có ý nghĩa giữa năng suất nguyên liệu và mật số vi sinh vật trên dụng cụ chỉnh hình giữa các nhà máy. Như vậy, vi sinh vật tồn tại với lượng cao trên dụng cụ chỉnh hình đặc biệt là các nhóm vi sinh vật Coliforms và $E$. coli sẽ làm tăng nguy cơ nhiễm chéo cho cá bán thành phẩm. Do đó, các nhà máy cần tăng cường tần suất vệ sinh nhà xưởng, các dụng cụ chế biến cũng như kiểm soát chặt chẽ hiệu quả của các quá trình và thủ tục vệ sinh, làm sạch và khử trùng trong và ngoài quá trình sản xuất (giữa các ca sản xuất).

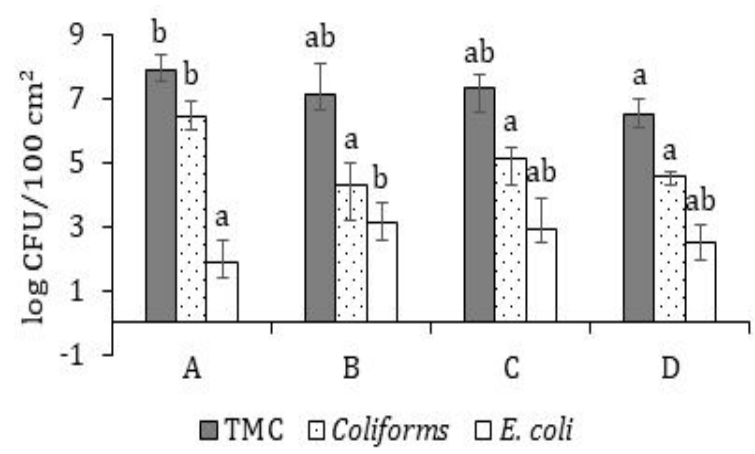

Hình 3. Mật số TMC, Coliforms và E. coli trên dụng cụ chỉnh hình.

Các chữ cái $(a, b, c)$ của cùng một chỉ tiêu vi sinh vật khác nhau thì các giá trị trung bình có sự khác biệt ý nghĩa thống kê ở mức 5\%. 


\subsection{Vi sinh vật tổng số, Coliforms, $E$. coli và Staphylococci coa+ trên cá chỉnh hình}

Mật số vi sinh vật tổng số hiếu khí, Coliforms, E. coli và Staphylococci coa+ trên cá chỉnh hình được thể hiện ở Hình 4. Nhìn chung, mật số vi sinh vật tổng số hiếu khí trên cá chỉnh hình $\geq$ $6 \log \mathrm{CFU} / \mathrm{g}$. Cụ thể, mật số trung bình của vi sinh vật tổng số hiếu khí trên cá chỉnh hình cao hơn $7 \log C F U / g$ tại hai nhà máy $A$ và $B$, và cao hơn ý nghĩa so với các mẫu cá chỉnh hình được lấy tại hai nhà máy $\mathrm{C}$ và $\mathrm{D}(P<0,05 ;$ mật số vi sinh vật tổng số hiếu khí trên cá chỉnh hình tại nhà máy $\mathrm{C}$ và $\mathrm{D}$ lần lượt là $6,7 \pm 1,1$ và $6,0 \pm$ $0,4 \log \mathrm{CFU} / \mathrm{g})$. Mật số Coliforms trên cá chỉnh hình tại các nhà máy dao động từ 4,0 - 5,5 log CFU/g, trong đó mật số Coliforms trên cá chỉnh hình thấp nhất tại nhà máy $\mathrm{A}$ và có khác biệt ý nghĩa so với các nhà máy còn lại $(P<0,05)$. Mật số $E$. coli trên cá chỉnh hình tại các nhà máy $\mathrm{A}$, $\mathrm{B}, \mathrm{C}$ và $\mathrm{D}$ lần lượt là $2,5 \pm 0,8 ; 3,7 \pm 0,6 ; 2,6$ $\pm 0,6$ và $2,5 \pm 0,4 \log \mathrm{CFU} / \mathrm{g}$. Trong đó, mật số E. coli trên cá chỉnh hình tại nhà máy $\mathrm{B}$ cao ý nghĩa so với các nhà máy còn lại $(P<0,05)$. Đối với Staphylococci coa+, mật số trên cá chỉnh hình tại các nhà máy dao động từ 1,8 - 4,2 log $\mathrm{CFU} / \mathrm{g}$, thấp hơn ý nghĩa tại nhà máy $\mathrm{A}$ so với các nhà máy còn lại $(P<0,05)$ (Hình 4$)$. Không có sự tương quan có ý nghĩa giữa năng suất nguyên liệu và mật số vi sinh vật trên cá Tra chỉnh hình giữa các nhà máy cũng như sự tương quan có ý nghĩa giữa điều kiện vệ sinh của môi trường chế biến (găng tay, dụng cụ chỉnh hình) và mật số vi sinh vật trên cá Tra chỉnh hình. Nghiên cứu của Noseda \& ctv. (2013) cho thấy mật số vi sinh vật tổng số hiếu khí trên cá chỉnh hình (năng suất nguyên liệu 200 tấn/ngày) dao động từ 3,0 - 4,1 $\log \mathrm{CFU} / \mathrm{g}$ và $E$. coli trên cá chỉnh hình $<0,7$ $\log \mathrm{CFU} / \mathrm{g}$.

Mật số vi sinh vật trên cá chỉnh hình cao có thể do lây nhiễm chéo từ găng tay công nhân, các bề mặt tiếp xúc. Ngoài ra, có thể do lây nhiễm chéo từ các công đoạn trước đó của quy trình chế biến (tiếp nhận nguyên liệu, phi lê, rửa). Ở công đoạn phi lê nếu thao tác của công nhân làm vỡ nội tạng cá thì nguy cơ gây mất an toàn cao công đoạn này và các công đoạn sau của quy trình chế biến. Từ các kết quả thu được, có thể thấy rằng mật số vi sinh vật trên cá chỉnh hình phụ thuộc vào quy trình chế biến và điều kiện vệ sinh (làm sạch và khử trùng). Lượng vi sinh vật trên cá (bán) thành phẩm cũng bị ảnh hưởng bởi các hoạt động kiểm soát chất lượng như thực hành vệ sinh cá nhân,

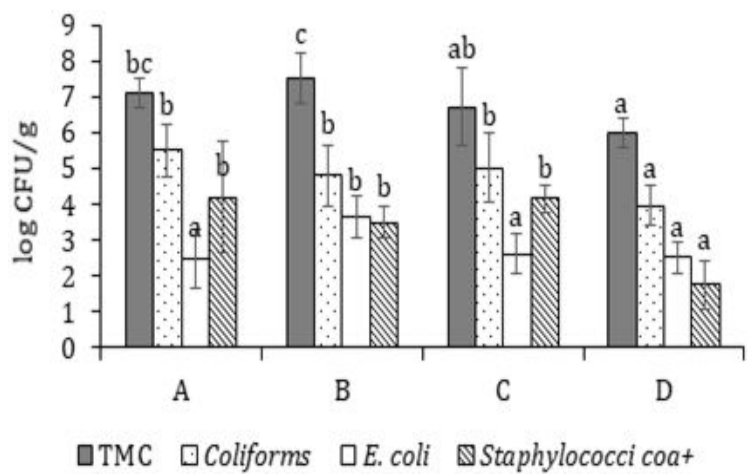

Hình 4. Mật số TMC, Coliforms, E. coli và Staphylococci coa+ trên cá chỉnh hình.

Các chữ cái $(a, b, c)$ của cùng một chỉ tiêu vi sinh vật khác nhau thì các giá trị trung bình có sự khác biệt ý nghĩa thống kê ở mức $5 \%$.

chương trình vệ sinh, các biện pháp phòng ngừa cho sản phẩm, kiểm soát nguyên liệu và phương pháp bảo quản cá bán thành phẩm (ShikongoNambabi \& ctv., 2010; Kulawik \& ctv., 2016). Từ các kết quả thu được, thực hành sản xuất tốt được đề nghị giám sát và có phương pháp bảo quản cá bán thành phẩm nhằm đảm bảo chất lượng và an toàn của cá bán thành phẩm.

\section{Kết Luận và Đề Nghị}

Tóm lại, mật số vi sinh vật tổng số hiếu khí trên cá chỉnh hình ở bốn nhà máy $\mathrm{A}, \mathrm{B}, \mathrm{C}$ và $\mathrm{D}$ lần lượt là $7,1 \pm 0,4 ; 7,5 \pm 0,7 ; 6,7 \pm 1,1$ và 6,0 $\pm 0,4 \log \mathrm{CFU} / \mathrm{g}$. Mật số Coliforms, E. coli và Staphylococci coa + trên cá tại các nhà máy tương ứng dao động từ $4,0-5,1 ; 2,1-3,7$ và $1,8-4,2 \mathrm{log}$ $\mathrm{CFU} / \mathrm{g}$. Đây là công đoạn cần giám sát và kiểm soát tốt nhằm hạn chế quá trình lây nhiễm cho cá bán thành phẩm. Các nhà máy chế biến cần cải thiện quy trình và thủ tục kiểm soát vệ sinh nhà xưởng, dụng cụ, thiết bị; thực hành tốt vệ sinh cá nhân và có phương pháp bảo quản cá bán thành phẩm để giảm thiểu khả năng gây mất an toàn cá bán thành phẩm.

\section{Lời Cam Đoan}

Nghiên cứu này không tồn tại bất kì mẫu thuẫn nào giữa các tác giả.

\section{Lời Cảm Ơn}

Nghiên cứu này thuộc khuôn khổ của đề tài A-16 tài trợ bởi dự án Nâng cấp Trường Đại học 
Cần Thơ VN14-P6 bằng nguồn vốn vay ODA từ chính phủ Nhật Bản. Nhóm nghiên cứu xin chân thành cảm ơn các nhà máy cho phép lấy mẫu và công bố các kết quả này.

\section{Tài Liệu Tham Khảo (References)}

Da Silva Meira, Q. G., de Medeiros Barbosa, I., Athayde, A. J. A. A., de Siqueira-Júnior, J. P., \& de Souza, E. L. (2012). Influence of temperature and surface kind on biofilm formation by Staphylococcus aureus from food-contact surfaces and sensitivity to sanitizers. Food Control 25(2), 469-475.

Di Ciccio, P., Vergara, A., Festino, A., Paludi, D., Zanardi, E., Ghidini, S., \& Ianieri, A. (2015). Biofilm formation by Staphylococcus aureus on food contact surfaces: Relationship with temperature and cell surface hydrophobicity. Food Control 50, 930-936.

ISO (International Organization for Standardization). (2004). Microbiology of food and animal feeding stuffs - horizontal methods for sampling techniques from surfaces using contact plates and swabs (ISO 18593:2004). Retrieved April 9, 2020, from https://www.iso.org/standard/39849.html.

ISO (International Organization for Standardization). (2003). Microbiology of food and animal feeding stuffs preparation of test samples, initial suspension and decimal dilutions for microbiological examination - part 2: Specific rules for the preparation of meat and meat products (ISO 6887-2:2003). Retrieved April 9, 2020, from https://www.iso.org/standard/29866.html.

Kulawik, P., Migdał, W., Gambuś, F., Cieślik, E., Özoğul, F., Tkaczewska, J., Szczurowska, K., \& Wałkowska, I. (2016). Microbiological and chemical safety concerns regarding frozen fillets obtained from Pangasius sutchi and Nile tilapia exported to European countries. Journal of the Science of Food and Agriculture 96(4), 13731379 .

Lang, M. M., Ingham, S. C., \& Ingham, B. H. (1999). Verifying apple cider plant sanitation and hazard analysis critical control point programs: choice of indicator bacteria and testing methods. Journal of Food Protection 62(8), 887-893.

Noseda, B., Thi, A. N. T., Rosseel, L., Devlieghere, F., \& Jacxsens, L. (2013). Dynamics of microbiological quality and safety of Vietnamese Pangasianodon hypophthalmus during processing. Aquaculture International 21(3), 709-727.
Novoslavskij, A., Terentjeva, M., Eizenberga, I., Valciņa, O., Bartkevičs, V., \& Bērziņš, A. (2016). Major foodborne pathogens in fish and fish products: A review. Annals of Microbiology 66(1), 1-15.

Shikongo-Nambabi, M. N. N. N., Chimwamurombe, P. M., \& Venter, S. N. (2010). Factors impacting on the microbiological quality and safety of processed hake. African Journal of Biotechnology 9(49), 8405-8411.

Shikongo-Nambabi, M. N. N. N., Shoolongela, A., \& Schneider, M. B. (2011). Control of bacterial contamination during marine fish processing. Journal of Biology and Life Science 3(1), 1-17.

Svanevik, C. S., Roiha, I. S., Levsen, A., \& Lunestad, B. T. (2015). Microbiological assessment along the fish production chain of the Norwegian pelagic fisheries sector-results from a spot sampling programme. Food Microbiology 51, 144-153.

TCVN (Vietnamese National Standards). (2005). TCVN 4830-1:2005: Vietnamese standard on microorganism in food and animal feeds - Method for determination of Staphylococcus aureus. Retrieved February 26, 2021, from https://vanbanphapluat.co/tcvn-4830-12005-dinh-luong-Staphylococci-co-phan-ung-duongtinh-coagulase.

Tong, T. A. N., Duyen, B. T. H., Loan, L. N. T. T., Nghia, L. D., Duy, L. N. D., Binh, L. N., \& Devlieghere, F. (2014). Comparison of Tra fish production process at seafood processing factories: microbial quality of total aerobic counts. Can Tho University Journal of Science 32 (2014), 69-75.

Tong, T. A. N., Phan, T. T. Q., \& Huynh, T. P. L. (2020). Textbook: Safety and pollution in food production. Can Tho City, Vietnam: Can Tho University Publishing House.

VASEP (Vietnam Association of Seafood Exporters and Producers). (2021). Value chain of Pangasius. Retrieved February 28, 2021, from http://vasep.com.vn/san-pham-xuat-khau/catra/nguyen-lieu/hinh-thanh-chuoi-gia-tri-nganh-hangca-tra-21000.html.

VASEP (Vietnam Association of Seafood Exporters and Producers). (2019). Overview of Vietnam fisheries industry. Retrieved April 1, 2020, from http://vasep.com.vn/1192/OneContent/tong-quannganh.htm. 